\title{
Stock Yield and Information Asymmetry
}

\author{
Ehsan Khansalar ${ }^{1}$, Mahmoud Lari Dasht-Bayaz ${ }^{2}$ \& Aref Miri ${ }^{2}$ \\ ${ }^{1}$ Kingston Business School, Kingston University, London, UK \\ ${ }^{2}$ Department of Accounting and Economics, Islamic Azad University, Qaenat Branch, Birjand, Iran \\ Correspondence: Ehsan Khansalar, Kingston Business School, Kingston University, London, UK. E-mail: \\ e.khansalar@kingston.ac.uk
}

Received: August 14, 2015

Accepted: September 28, 2015

Online Published: October 25, 2015

doi:10.5539/ijef.v7n11p250

URL: http://dx.doi.org/10.5539/ijef.v7n11p250

\begin{abstract}
One of the most fundamental economic problems is optimal allocation of resources towards high-yield investments with reasonable risk. For this achievement, it is required to have operational evaluation criteria that some of which emphasize on cash flow variables and some others on the information content of accounting interest. In order to achieve this end, in this study, the relationship between yields before interest and tax and operational cash flow with shareholders' output in information asymmetry conditions during the life cycle of the listed companies in Tehran Stock Exchange was investigated. To do testing hypotheses, multiple pooled data Regression was used. To separate the companies through life-cycle, Anthony and Ramesh's (1992) research was used. The results of empirical tests results, by using information related to 142 firms during 2008 to 2013 , indicate that in each of three stages of growth-maturity and the firms' fading and interest before benefit and tax-have no positive and significant relationship with the output of the firms' stock on the other hand, the interest before benefit and tax rather than operational cash flow have more information content.
\end{abstract}

Keywords: information asymmetry, accruals, cash flow, total shareholder returns, life cycle

\section{Introduction}

The investors for decision making about economical issues, by their own, need economical information regarding the companies. The main part of informational needs in investors is supplied by financial bills. The investors using application indicators such as accounting interest, cash flows and Etc are investigating the companies' operation. In complete rivalry situations which exists informational clarity the accounting interest in proportion to cash flows have more informational content in explanation of market performance on the other hand, according to Daglas theory, by moving from traditional market to new community, the amount of lack of information asymmetry increases because, the more developed the community is, the more will be job division and profession therefore, product variations increases the growth of profession and job division and information asymmetry( the experts having such information but, others lack). The novice investors have lesser capabilities for financial analysis of information as a result; in the conditions of existing information asymmetry they will undergo more losses.

\subsection{Statement of the Problem}

By considering the conditions of information asymmetry in capital market, it seems that the variables of cash flow in proportion to accounting interest have more information content in explaining of capital market. On the other hand, one of the economical features is the life cycle of the company. According to life cycle theory, the companies in different stages of life cycle economically and financially have appearances and especial treatments in a way that financial and economical features of a company is influenced by a stage of life cycle which company is located in so, to this reason, in this survey, the relationship between the interest prior to interest, tax and cash flow with shareholders' yields during the lifecycle of the companies in Tehran's stock exchange market is investigated.

\section{The Theoretical Principals and Literature Review}

The investors for yield allocations of their financial resources toward highly yield investments with logical risk need a true recognition of business unit however, they are often searching for information relating to business unit so that based on it, make a true decision. Financial reporting is from the most important techniques for true 
users' decision makers of information which for the investors and recent and potential creditors in making investing decisions, crediting, price evaluation, timing and lack of insurance regarding next cash flows (such as paying stock yield and interest) and also in reporting of economical resources, the claim regarding to these resources, the effect of exchanges and effective event on resources to be beneficial (the manifesto of number 1 concepts, the goals of financial reporting by business units. From practical viewpoints, the accounting interest has been defined as "the difference between the accomplished earning because of period exchanges and related historical expired cost" the accounting interest based on the commitment and accepted principals of accounting is being adopted. Generally, we can say that the goal of interest measuring is determining business unit as a result of performances that has done during a determined time and how much has improved. That's why, the issue of interest is usually equal to improvement of business unit states and as result, the more the interest price is, the more you can expect improvement in business situation unit. The necessity of interest reporting as a primary source for investors' decision making has been well documented and interest reporting in different methods such as offering bases for tax calculation, a criteria for the firm's successful operation, a criteria for evaluation of sharing interest, a criteria for interest distribution management, a criteria for managing an economical unit and other cases which help the economy of society and also, because the value of a company is being associated with now and future interests. Determining interest is very important (Kordestani \& Hedayati, 1389). There are varieties of systems for interest determination that for theoretical reasons are accounted as accepted general principals. Any system that for measuring the interest of a company for a specific accounting period are used, by its own, has mixed capital surveillance as well as a measuring method of property/debt (Nourvash et al.). The accounting interest that is provided by a committal system, according to most users of financial bills is accounted as a means for measuring the company operations and the goal of measuring the firms' performances is overall evaluation of financial states as well as operational results for making logical decisions. As example, the accounting interest can be regarded as the base of the banks credit-giving to the firm or it can be mentioned as conditions for entry into stock exchange. The groups of financial accounting standards, in financial accounting concepts of number 6 have necessitated using committal method in accounting. Based on this, the reflection of the trading outcomes and the firm's events is not necessarily mean the cash flow's input-output on the other hand, in committal method, principals such as "accomplishment" and "accordance" for reflecting incomes and the costs and calculating the interest of accounting is being used. Ultimately, a firms' success is depend on its capability in making cash flows (the groups of financial accounting standards, 1985). From accounting viewpoints, due to available ambiguities regarding the amount of the next cash flows and lack of accessing to interest rate, the capital is measured based on net income of financial properties. On the other hand, in accounting, it is because of the difference between the capital of business unit in the outset and the end of the period. In this concept, the capital is equal to net assets and measuring net is affected by the principals of properties and debts. In accounting for determining the interest, different methods such as committal accounting, cash accounting, partly-committal accounting and the adjusted committal has been used. It is clear that using the above methods will offer different benefits and loses and to this reason, according to the principal of accordance, the accouters for recognition of the costs follow the approach of (let the costs to follow the incomes). According to this principal, the costs of a period are deducted from the incomes of the same era so that a real operation is being resulted from outcome. From theoretical points of view, a correct method of accounting, for recognition of income, must be in a way that first that income is being obtained or being achievable and secondly, that income is being obtained. According to this version, if one of the above conditions happens, we can recognize the income Littleton (1380). The operational cash flows are one of the important criteria of performance evaluation from the viewpoints of inner-organization or outside-organization and especially the investors and creditors. In theoretical framework, financial accounting which is determining the goals of financial reporting, have paid special attention to cash flows and its possibility of prediction.

In the manifesto of financial accounting concepts of number 1, a providing group of financial accounting standards has been stated. One of the goals of financial reporting is providing information which help the investors, creditors and other potential and active users in estimating the price, timing and the risks of future receiving. The prospects of these cash flows under the influences of the firm's capabilities in producing enough cash flow to demand its commitments to usance and other cash operations such as paying cash interest of the stock and also under the influences of the investors' public tendencies is related to those capabilities that affect stock market (FASB, 1978). The committee of international standards of accounting (IASC) has also been mentioned in international standards of accounting of number 7 that:

Information related to cash flows currencies is a business unit for users of financial inventory in providing a base for evaluation of its power in making cash flows and the needs of that unit in using these founds are useful. And also economical decisions made by users are required evaluation of a business unit in making cash fund, timing 
and assurance of it IASC (1993). The committee Iran's accounting standards in theoretical concepts of financial reporting has stated that "making economical decisions by users of financial inventories requires evaluation of business unit power in making cash payment and certainty of making it. The evaluation power of making cash by concentrating on financial situation, financial operation and business unit cash flows and predicting the expected cash flows and measuring financial flexibility is also being facilitated (the committee of accounting standards 1386). Investigating theoretical principals and financial reporting showing this subject that one of the goals of financial reporting is helping investors and creditors for predicting the next cash flows. The financial inventories are regarded as the main product of financial reporting and the means of transferring accounting information to the individuals outside the organization.

This idea that financial inventories to what extent could achieve this important goal so, it is a question that have usually been considered by researchers and theorists however, there are disagreements regarding what kind of financial information for predicting cash flows are beneficial. Investigation of topic shows that some of the theorists and the authorities of preparing theoretical principals and financial reporting objectives believe that by using accounting interest and its parts, we can predict cash flows. As example, the provider staffs of financial accounting standards of America believe that "often providing information regarding interest and its parts in proportion to cash flow and for predicting the next cash flows have the more predicting potentialities" (FASB ,1978). Widespread investigations have happened regarding this issue and in most of them interest and cash flow as predicting criteria of the future cash flows expected by the share holders has been used but, superiority of interest regarding cash flow in predicting the future cash flow of the firm is still a secret. The concept of life cycle declares that most of live creatures including plants, animals and the men all of them are following lifetime curve so, these creatures are born, get old and ultimately they die. The organizations like live creatures have lifetime curve or lifecycle on the other side, in each stage of the stages of this period they have the problems of their own and on the other hand, in transferring stages between the periods they face specific problems, too. The organizations usually in their moving flow are continually facing many problems that usually are solved by inner organization powers. But, sometimes, problems happen that inner power can not solve them and to solve them, a professional outside the organization interference is inevitable.

Like live creatures, the growth and oldness of organizations are first shown by controlling and flexibility however, they are very influential in renewing the organizations but, in most cases are uncontrollable. By the organizations' aging, the relations change, controlling boosts and flexibility reduces.

Aging and long lifetime are not the reasons for development and aging however, there are big firms with long life which are considered as young or aged. Young does not mean that organization easily changes and on the other hand, due to lack of prediction possibility, there is at the lowest level of control. Old means behavior sense of controlling while, there has not been any flexibility as well as tendency to change. When one of the traders sides to other have information advantage then, they say that economical system from information view is asymmetry. In accounting theory, the theory of information asymmetry is very important because, the markets of stock exchange are affected by the issue of information asymmetry and it is due to inner organization information. Even if the price reflects all information available in the market, it is likely that individual in the organization rather than outside the organization have more information. So, at this time, these individuals use the advantage of using this information and get more benefits. When the foreign investors know this issue, it is evident that the sum they were supposed to pay (by perfect information) for stock exchange, they don't pay and because of that they react to the likely confidential information. (1386 Scot). In a world by information asymmetry, it is supposed that the managers and the market have equal information regarding the firms or they have no specific information about it thus, the managers and market can bear uncertainty about culture. But, in the world with lack of information asymmetry the managers have more and better information than market, due to having private and confidential information. That's why, they access to private information of the firm before the markets' notice. The lack of information asymmetry of the firm is equal to total uncertainty regarding the company because, it is likely that the managers and the market to be equally aware of the market's variables influences on the firms' value. The markets reaction to interest can be the first criteria for lack of information asymmetry of the firm by information disclosure.

Lack of information asymmetry can be based on information setting, excessive public show and the number of the firm's transactions is being determined and also, can be influence by the managers' treatments or the market.

Reborn (1986), in his survey, studied the relation ship between the unexpected components of committal interest and cash flows with stock yield. So, the study results show that parts, accounting interest and cash flows have information contents. 
Asheq Ali, (1994) in his study, investigated the increasing information interest contents and capital in the cycle as results of operations and cash flows. The study results, show the increasing information contents of interest to capital in the cycle as result of operations and cash flows.

Wilson (1987) in his survey, by separating cash components and committal interest, investigated the role of information content of interest components in relation to the interest itself. The results show that committal components of interest have increasing contents of information in proportion to its cash components

Subramanyam (1996) in his study, investigated cash flows informational content in American capital market. The study result is representative of increasing information contents in committal and cash flows to each other including arbitrative multi users for the cash found obtained from operations having increasing information.

Stiffen Repp (2010) in his study, investigates the relationship between accounting interest and cash flows with shareholders' benefits in the condition of information asymmetry. The study results show that, in information asymmetry conditions, the accounting interest in proportion to cash flows enjoys more information contents but, by increasing information asymmetry the criteria for cash flows is more relates in explanation of capital market operation. Nouroosh and Mashayekhi (1383) in their study under the title of "the increasing information content of economical and cash surplus value verses accounting interest and cash founds as result of operations" investigated surplus value increasing information content verses accounting interest and cash flows obtained by operations. For this end, they tested between the stock yield and data changes relating to economical surplus value, cash surplus value, accounting interest and cash flows resulted by operations for accepted productive firms in Tehran's stock exchange in 1375-1381. The history was representative of this that accounting interest is the most accounting variable in financial decisions as well as investment and in most cases have increasing information content in proportion to other variables. Wan et al. (2009) in a paper titled as "the hypothesis of lifecycle and the policies of interest division" studied the policy of interest division and the hypothesis of lifecycle. The results showed that paying stock interest in younger trading units with high growth power but, lower benefit which leads to interest distribution in a form of sharing interest to cash flow. When the trading units get more developed, the power of low growth and high benefit power also leads to more cash distribution verses sharing yield. Gorbani, in his paper as "investigating the relationship between interests and free cash flows with the firm's value in the frame work of life cycle" and the relation of interest and cash flows with the company value in the frame work of the firm's lifetime cycle. His finding showed that in growing and fading stages the relation of cash flows with the firm's value is more powerful than the interest relation with the firm's value and in the maturing stage the opposite is true. Bahatacharia et al. (2010) in his research studied the relationship between interest quality and information asymmetry. The research results show that low quality of interest causes increasing information asymmetry in financial market. Their study results show that between proposing different price scope of stock exchange as representative information asymmetry and committal items no significance difference was observed. Dichu et al. (1998) in his research studied the relationship between interest and cash flows in New York stock exchange market. The study results are indicative that historical interests in proportion to historical cash flows are a better predictor of operational future cash flows.

Gaemi, Nouzari, Rahimpour and Rouhi (1389) in their researches as "seasonal interest and information asymmetry "studied the relationship between the effects of seasonal interest and information asymmetry. The study results by investigating 555 seasonal interests related to 157 accepted firms in Tehran's stock exchange is indicative that after exposure of seasonal interests the information asymmetry has not considerably reduced. So, regarding the topic, the research hypothesis is offered as follow:

Hypothesis 1: By considering information asymmetry in the stages of the firms' development, the operational cash flow in proportion to the benefit before the interest and tax has more effect on the firm's stock yields.

Hypothesis 2: By considering information asymmetry in the firms' maturing stage, the operational cash flow has more effect on the firm's stock yields.

Hypothesis 3: By considering information asymmetry in the firms' fading stage, the operational cash flow has more effect on the firm's stock yields.

\section{Methodology}

This research in terms of goal is applicatory and in terms of method is descriptive-correlative. In this research, to collect information, Rah Avard Novin and Tadbir Pardaz software and also the web net base of Tehran's stock exchange has been used. For analysis and the tests of research hypothesis EVIEWS 7 economical software has been used.

Regarding the proposed sampling method, 142 firms was selected as sample that out of which 60 firm in 
developing stage, 44 firm in the maturing stage and 38 of them were in fading stage. The present research is correlative type because, it testes the relation between dependent and independent variables. In this research, by using multi-model Regression and F, T hypothesis will be tested (panel Data Analysis). In this research, for the test of research hypothesis, Regression pattern of multi-variable based on mixing data method is used. To determine mixing data method, first F useful Limer was used. Supposing zero for this test is based on method of mixing data and the following hypothesis emphasizes on using mixing data method. Then, another test based on being random or stability of time effects and levels are conducted. Zero supposing of this test is based on random time in pattern processing and current hypothesis is indicative of time stability. So, for hypothesis test the following economic measuring was used.

$$
\begin{aligned}
R_{i t}=\alpha_{0}+\beta_{1} x E A R_{i t}+\beta_{2} x C F_{i t}+ & \lambda_{1} x B E T A_{i t}+\lambda_{2} x S I Z E_{i t}+\lambda_{3} x M T B_{i t}+\lambda_{4} x E T P_{i t}+\lambda_{5} x L E V_{i t} \\
& +\lambda_{6} x D O M I N A T E D_{i t}+\varepsilon_{0}
\end{aligned}
$$

The dependent and independent variables of the survey are:

$R_{i t}=$ the shareholders' percent of yield;

$C F=$ the operational cash flow in of i $\mathrm{M}$ in $\mathrm{T}$ year;

$B E T A=$ Systematic risk;

$S I Z E$ = the size of all the company calculated by all assets' Logarithm;

$M T B_{i t}=$ the proportion of market value to the salary of all stock holders;

$E T P_{i t}=$ the proportion of each share to the price of stock market;

$L E V_{i t}=$ all the firm's debt divided on total assets;

$\alpha_{0}=$ the fixed value of the model;

$\beta_{1}, \beta_{2}, \lambda_{1}, \lambda_{2}, \lambda_{3}, \lambda_{4}, \lambda_{5}, \lambda_{6}=$ the coefficients of independent variables;

$\varepsilon_{0}=$ to consider information asymmetry, figurative variable (Dominated) is used which is discussed briefly down.

$D_{\text {DOMINATED }}$ it $=$ if the firm's floating share is less than $50 \%$ the amount of 1 is considered zero.

To consider lifecycle of the firms, Antony \&Ramesh research was used. Antony \& Ramesh in their paper to divide the firms into lifecycle used four variable of sale growth, capital cost, the proportion of dividing share and the age of the firm. The base of the firm's divisions to stages of lifecycle in this study is similar to the used methods in the targeting papers except, the variable of the firm's cycle has been omitted.

The classification method based on three variables is as follow.

First, the values of three above variables for each firm, the calculated year of the firms based on three low, middle and upper medium and for each of the observations placed in three classes, a number was dedicated.

For each firm, annually a mixed score is obtained that in respect to Table 1, in each of 3 stage of growth, maturity and fading is classified. Since, the adopted firms in Tehran's stock exchange have no history of activity and this subject is part of the firms' acceptance, is not considered as stage of birth. Finally, the observations which based on the mentioned variables and in the framework of lifecycle are not placed are omitted from the first sample and the rest form the final sample.

Table 1. Lifecycle classification

\begin{tabular}{lcccc}
\hline The stages of lifecycle & Number of firms & Sale growth (SG) & The proportion of division profits (DPR) & Capital expenses (EC) \\
\hline Growth (G) & 47 & 3 & 1 & 3 \\
Maturity (M) & 27 & 2 & 2 & 2 \\
Sunset (S) & 59 & 1 & 3 & 1 \\
\hline
\end{tabular}

The way of calculating the above variables are as follow:

Sale(sgit) the proportion of dividing profit (DPRIT) and capital costs (CEit) for each year on the company is used by following formula.

$$
\text { SGit }=\left(\frac{S t}{S t-1}-1\right)
$$




$$
\begin{gathered}
\text { DPRit }=\frac{D P S t}{E P S t} \\
\text { CEit }=\frac{\Delta P P E t-\Delta C E t}{M V t-1}
\end{gathered}
$$

In the above formulas st-1, ST are income of the firm's sale respectively in t,t1 period also, DPS, EPS is regarded as cash profit and the profit of each share is in t period. And, also $\triangle \mathrm{PPE}$ is equivalent to the net changes of total fixed assets in period of $t$ and MV $t-1$ equivalent to the value of stock exchange market in $t-1$

\section{The Research Findings}

In the second table the descriptive statistic related to the researches' variable.

Table 2. The description of the indices of central tendencies and the dispersal of studding variables

\begin{tabular}{lccccccccc}
\hline The name of the indices & DOMINATED & LEV & ETP & MTB & SIZE & BETA & CF & EAR & R \\
\hline medium & 0.770414 & 0.630257 & 0.149860 & 3.235199 & 11.71782 & 0.492736 & 244519.8 & 282915.2 & 107.5097 \\
median & 1.000000 & 0.636544 & 0.149873 & 1.845935 & 11.66988 & 0.560000 & 43868.56 & 52018.00 & 75.81204 \\
maximum & 1.000000 & 0.983126 & 2.213974 & 116.6568 & 13.71366 & 3.160000 & 10534653 & 8040108. & 923.2684 \\
minimum & 0.000000 & 0.168869 & -1.66095 & -8.304715 & 10.58852 & -2.31 & -2418159 & -717929 & -289.26 \\
Standard deviation & 0.420816 & 0.192241 & 0.227061 & 7.008035 & 0.607925 & 1.641479 & 1012416. & 942523.5 & 130.6198 \\
Number of observations & 0.770414 & 0.630257 & 0.149860 & 3.235199 & 11.71782 & 0.492736 & 244519.8 & 282915.2 & 107.5097 \\
\hline
\end{tabular}

As it has been shown in Table 2 the central medium indices and medium and the index of standard deviation and also, maximum and minimum data are has been tested so, the mean and median is indicator of variable asymmetry distribution. This characteristic is very important because it is one of the distribution characteristics in addition, it is observed that medium plus standard deviation is put between minimum and maximum variables.

Before estimating search models, the relationship between the researches variables are investigated so, to achieve this, Pearson correlation is used.

Table 3. Pearson correlation between independent studding variables

\begin{tabular}{ccccccccc}
\hline Research Variables & DOMINATED & LEV & ETP & MTB & SIZE & BETA & CF & EAR \\
\hline EAR & 0.083 & -0.016 & 0.014 & -0.028 & 0.056 & -0.06 & 0.087 & 1 \\
CF & 0.071 & -0.103 & 0.091 & -0.030 & 0.047 & -0.023 & 1 & 0.087 \\
BETA & 0.079 & -0.029 & -0.0653 & -0.026 & -0.051 & 1 & -0.023 & -0.06 \\
SIZE & 0.144 & 0.014 & 0.117 & -0.005 & 1 & -0.051 & 0.047 & 0.056 \\
MTB & 0.032 & 0.134 & -0.013 & 1 & -0.005 & -0.026 & -0.030 & -0.028 \\
ETP & -0.01 & -0.23 & 1 & -0.013 & 0.117 & -0.0653 & 0.091 & 0.014 \\
LEV & 0.067 & 1 & -0.23 & 0.134 & 0.014 & -0.029 & -0.103 & -0.016 \\
DOMINATED & 1 & 0.067 & -0.01 & 0.032 & 0.144 & 0.079 & 0.071 & 0.083 \\
\hline
\end{tabular}

As it has been shown in Table 3, there is no significant correlation between the independent variable of the research. Therefore, placing these independent variables near to each other does not make problem when making a test in Regression processing.

To increase the number of observations, rising level of freedom, reducing the variance inequality and reducing co-lining among variables, the method of mixed data has been used. First the possibility of data combining was investigated. To do this, F Limmer test was used. The construction of this hypothesis test is as follow:

H0: The width parameters from the beginning are equal in all places.

$\mathrm{H} 1$ : The width parameters from the beginning are not equal in all places.

Table 4. The results of F Limer (equity of width from the beginning point)

\begin{tabular}{llll}
\hline & Significant level & Patterns & H0 hypothesis \\
\hline In all patterns Ho hypothesis & .0000 & Pattern (1) & The width of beginning \\
is rejected & .0000 & Pattern (2) & in all crosses is the \\
& .0000 & Pattern (3) & same. \\
\hline
\end{tabular}


Regarding the results of Table 4, the calculating method in this research will be Pannel Data and the method of Pooling Data will be correct. Then, in order to determine the fixed outcomes and random, Hasman Test was conducted. In this test by accepting Ho hypothesis, random patterns are used. The jest of Housman Test results has been offered in Table 5. Regarding the significant level of all patterns, Ho hypothesis is rejected and implicates on fixed outcomes.

Table 5. The results of Housman results

\begin{tabular}{|c|c|c|c|c|c|}
\hline Test results & Significant level & Degree of freedom & statistic $\chi 2$ & Surveying patterns & hypothesis H0 \\
\hline In all patterns $\mathrm{Ho}$ & .000 & 8 & 102,454 & Pattern (1) & \multirow{3}{*}{$\begin{array}{l}\text { The difference is not in } \\
\text { systematic coefficients }\end{array}$} \\
\hline Hypothesis Is & .0027 & 8 & 23,539 & Pattern( 2) & \\
\hline rejected & .0000 & 8 & 856,43 & Pattern (3) & \\
\hline
\end{tabular}

The analysis result shows that the relation between independent and dependent variables in this study have more determination power than time involvement on the other hand, in models' estimation the width of starting point are unequal and there is significant relationship between the related part and explanative variables. To investigate normality of data distribution Kolmogorov and Smirnoff is used. The test construction is as follow;

H0: Data distribution is normal.

H1: Data distribution is not normal.

Table 6. The results of Kolmogorov and Smirnoff tests

\begin{tabular}{lcc}
\hline Variable name & Significant level & The statistic of Kolomogorev and Smirnoff \\
\hline Growth stage (Rit) & .548 & .0369 \\
Maturity stage (R it) & .361 & .0184 \\
Sunset stage (R it) & .803 & .0742 \\
\hline
\end{tabular}

Regarding the significant level of dependent variables which is more out of 5 percent error , is confirmed so, this kind of data distribution is normal.

The test of the first hypothesis:

The first hypothesis defined as "by considering information asymmetry in the firm's developing growth, the operational cash flow regarding the profit before interest and tax have more influence on the firm's stock exchange.

The results obtained by analyzing this hypothesis has been offered in Table 7 .

Table 7. The results of analyzing hypothesis 1 ( pattern 1 )

\begin{tabular}{|c|c|c|c|}
\hline \multicolumn{4}{|c|}{$\mathrm{R}_{\mathrm{it}}=\alpha_{0}+\beta_{1} \mathrm{xEAR}_{\mathrm{it}}+\beta_{2} \mathrm{xCF}_{\mathrm{it}}+\lambda_{1} \mathrm{xBETA}_{\mathrm{it}}+\lambda_{2} \mathrm{xSIZE}_{\mathrm{it}}+\lambda_{3} \mathrm{xMTB}_{\mathrm{it}}+\lambda_{4} \mathrm{xETP}_{\mathrm{it}}+\lambda_{5} \mathrm{xLEV}_{\mathrm{it}}+\lambda_{6}$ dummy DOMINATED $_{\varepsilon}+\mathrm{e}$} \\
\hline The variables & Significant level & Statistic & Coefficient \\
\hline Fixed value & .000 & 7,304 & 669,357 \\
\hline The interest before the benefit and tax & .000 & 9,358 & .039 \\
\hline The operational cash flow & .115 & $-1,580$ & -.019 \\
\hline Systematic risk & .231 & 1,200 & .638 \\
\hline The firm's size & .000 & $-6,352$ & 48,553 \\
\hline The proportion of market value to share holders' salary & .000 & 8,935 & 5,679 \\
\hline The proportion of each share to the price of stock market & .000 & 5,538 & 111,235 \\
\hline Total debt of the firm divide to all assets & .009 & $-2,595$ & $-35,650$ \\
\hline Figurative dominated variable & .003 & $-3,016$ & $-14,530$ \\
\hline \multicolumn{4}{|l|}{ determining coefficient $=87.01 \%$ The determining coefficient $=84.01 \%$} \\
\hline \multicolumn{4}{|l|}{ Durbin Watson: $1 / 6$} \\
\hline Statistic $\mathrm{F}=28.995$ possibility $=. / 0000$ & & & \\
\hline
\end{tabular}

Table 7, 87.01 percent of the changes of the firm's stock in growing stage used in independent variables is being explained in the above model and the value of justified coefficient has been calculated regarding sample size and 
community of 84.01 in addition, in the growing stage of the firms, it is observing that the effect of independent interest variable before benefit and tax on the firms' stock is .039 , positive and significant, the influence of independent variable of the firm's size on the firms' output and finally, $-48,553$ negative and significant. The effect of market value proportion variable to stock holders is 5.679 which are significance and positive however, the effect of variable of each interest share to the price of stock market and also on the output of the firms is 111.235 significant and positive, the effect of total debt variable to divided to all assets on the output of all the firms which is negative and significant and the effects of figurative variables Dominated on the output of the firms' stock is -14.530 which is negative and significant relationship. The rest of independent variables have no independent effect on the firm's output. The statistic of Durbin Watson has been calculated 1/6 which is indicative that error parts in this model have not had significant correlation and have independent treatment. On the other hand, between the observation errors, there is no correlation. The value of calculated $\mathrm{F}$ in Regression model is 28/995 which is observed which regression is significant and supposing $\mathrm{H} 1$ is rejected.

The test of the second hypothesis:

The second hypothesis "by considering information asymmetry in the maturing stage of the firms, the operational cash flow in proportion to the interest before tax and interest have more influence on the output stocks of the firms"

The obtained results of analyzing this hypothesis has been mentioned in Table 8 .

Table 8. The results of analyzing hypothesis 2 ( pattern 2)

\begin{tabular}{|c|c|c|c|}
\hline \multicolumn{4}{|c|}{$\mathrm{R}_{\mathrm{it}}=\alpha_{0}+\beta_{1} \mathrm{xEAR}_{\mathrm{it}}+\beta_{2} \mathrm{xCF}_{\mathrm{it}}+\lambda_{1} \mathrm{xBETA}_{\mathrm{it}}+\lambda_{2} \mathrm{xSIZE}_{\mathrm{it}}+\lambda_{3} \mathrm{xMTB}_{\mathrm{it}}+\lambda_{4} \mathrm{xETP}_{\mathrm{it}}+\lambda_{5} \mathrm{xLEV}_{\mathrm{it}}+\lambda_{6}$ dummy DOMINATED $_{\varepsilon}+\mathrm{e}_{\mathrm{c}}$} \\
\hline The variables & Significant level & Statistic & Coefficient \\
\hline Fixed value & .000 & 4,578 & 914,737 \\
\hline The interest before the benefit and tax & .000 & 6,212 & .0001 \\
\hline The operational cash flow & .084 & $-1,734$ & .008 \\
\hline Systematic risk & .183 & 1,336 & 1,083 \\
\hline The firm's size & .000 & $-3,958$ & $74,840-$ \\
\hline The proportion of market value to share holders' salary & .078 & 1,774 & .224 \\
\hline The proportion of each share to the price of stock market & .000 & 9,344 & 124,942 \\
\hline Total debt of the firm divide to all assets & .757 & -.310 & $10,924-$ \\
\hline Figurative dominated variable & .079 & 1,768 & 7,327 \\
\hline \multicolumn{4}{|c|}{ Determining coefficient $=79.29 \%$ the determining coefficient $=74.28 \%$} \\
\hline \multicolumn{4}{|c|}{ Durbin Watson : $1 / 6$} \\
\hline Statistic $\mathrm{F}=15,839 \quad$ possibility $=. / 0000$ & & & \\
\hline
\end{tabular}

As it was observed in Table 8, 79.29 percent of the changes of the firm's stock outputs in maturing stage have been used by independent variables and will be explained in the above model and the value of determined coefficient regarding sample size is calculated 74.28 in addition, in the maturity stage of the firms the effect of independent variable of the company on the firms' stock output is $-74,840$ negative and significant and also, the effect of dependent variable of each share to the price of stock market on the firm's output stock is 124.942 positive and significant so, the rest of independent variables have no significant effect on the output of the firms' stocks. The statistic of Durbin Watson is calculated 1/6 which indicates that error parts in this model have not had significant correlation and have independent treatment to each other. On the other hand, there is no correlation between parts of error observations. The value of calculated $\mathrm{F}$ statistic in processed Regression model is $15 / 855$ that according to level of significance in Table. $/ 000$ is observed and totally Regression is significant and hypothesis $\mathrm{H} 1$ is rejected.

The third hypothesis:

The third hypothesis defined as "by considering lack of asymmetry in the firms fading stage, the operational cash flow in proportion to the benefit before interest and tax have more influence on stock out put of the firms.

The analyzing results of this hypothesis has been offered in this Table 9. 
Table 9. The results of analyzing hypothesis 3 ( pattern 3)

\begin{tabular}{|c|c|c|c|}
\hline \multicolumn{4}{|c|}{$\mathrm{R}_{\mathrm{it}}=\alpha_{0}+\beta_{1} \mathrm{xEAR}_{\mathrm{it}}+\beta_{2} \mathrm{xCF}_{\mathrm{it}}+\lambda_{1} \mathrm{xBETA}_{\mathrm{it}}+\lambda_{2} \mathrm{xSIZE}_{\mathrm{it}}+\lambda_{3} \mathrm{xMTB}_{\mathrm{it}}+\lambda_{4} \mathrm{xETP}_{\mathrm{it}}+\lambda_{5} \mathrm{xLEV}_{\mathrm{it}}+\lambda_{6}$ dummy DOMINATED ${ }_{\varepsilon}+\mathrm{e}_{0}$} \\
\hline The variables & Significant level & Statistic & Coefficient \\
\hline Fixed value & .000 & 16,616 & 1106,500 \\
\hline The interest before the benefit and tax & .000 & 11,993 & .029 \\
\hline The operational cash flow & .152 & $-1,440$ & -.008 \\
\hline Systematic risk & .336 & .964 & .833 \\
\hline The firm's size & .000 & $-14,046$ & $-87,362$ \\
\hline The proportion of market value to share holders' salary & .416 & .816 & .198 \\
\hline The proportion of each share to the price of stock market & .000 & 6,671 & 165,487 \\
\hline Total debt of the firm divide to all assets & .353 & .931 & 26,834 \\
\hline Figurative dominated variable & .062 & $-1,881$ & $-17,147$ \\
\hline \multicolumn{4}{|c|}{ Determining coefficient $=99.83 \%$ the determining coefficient $=87.18 \%$} \\
\hline \multicolumn{4}{|c|}{ Durbin Watson : $1 / 6$} \\
\hline Statistic $\mathrm{F}=27.348$ possibility $=0000 . /$ & & & \\
\hline
\end{tabular}

As it was observed in Table 9, 87.18 percent of the changes of the firm's stock outputs in maturing stage have been used by independent variables and will be explained in the above model and the value of determined coefficient regarding sample size is calculated 83.99 in addition, in the maturity stage of the firms the effect of independent variable of the company on the firms' stock output is $-87,362$ negative and significant and also, the effect of dependent variable of each share to the price of stock market on the firm's output stock is 1654.487 positive and significant so, the rest of independent variables have no significant effect on the output of the firms' stocks. The statistic of Durbin Watson is calculated 1/6 which indicates that error parts in this model have not had significant correlation and have independent treatment to each other. On the other hand, there is no correlation between parts of error observations. The value of calculated F statistic in processed Regression model is $27 / 348$ that according to level of significance in table.$/ 000$ is observed and totally Regression is significant and hypothesis $\mathrm{H} 1$ is rejected.

Investigating normality of the distribution of the rest:

One of the points that when working with Regression we must consider it, is normality of the rests so, to this reason, Jarkoo test to investigate normality of the rest of variables are used. The construction of this hypothesis test is:

H0: The distribution of the rests is normal.

$\mathrm{H} 1$ : The distribution of the rests is not normal.

The results of Jarkoo Test has been offered in Table 10.

Table 10. The results of Jarkoo test

\begin{tabular}{lccl}
\hline H0 hypothesis & Significant level & pattern & Ho hypothesis \\
\hline In all patterns Ho is confirmed & .328 & Pattern (1) & \\
& .645 & Pattern (2) & The distribution of the rest is normal \\
& .738 & pattern (3) & \\
\hline
\end{tabular}

As it is observed in Table 10, because the significant level is prone to error so, supposing Ho is confirmed then, the rest of variables have normal distribution.

\section{Summery and Conclusion}

The investors, in order to decide about economical issues, they, themselves, need economical information regarding the companies. A main part of information needs of the investors is provided by financial bills however, the capitalists, using operational indices such as accounting interest, cash flows which interpret from these financial bills, investigate the firms' operation. In the conditions of complete rivalry which is information clarity, accounting interest in proportion to cash flows have more information content in distribution of capital market operation. By considering the condition of the information asymmetry in capital market, it seems that the variables of cash flow in proportion to accounting interest have more information content in explanation of capital market operation. On the other hand, it is one of the economical characteristics the firms' lifecycle. 
According to lifecycle theory, the firms in different stages of lifecycle have specific plans and treatments financially or economically therefore, it means that financial and economical features of a firm is influenced by a stage of lifecycle which the company is placed. To this reason in this study, the relationship between the interest before the benefit and tax and operational cash flow and shareholders' output during lifecycle of the firms in Tehran stock exchange has been investigated. Using economic measure models, the research hypothesis is tested. The research results show that in each three stage, maturity, fading of the firms, interest prior to benefit and tax have positive and significant relationship with the output of the firms' stock while, the operational cash flow have no significant relationship with the output of the firms' stock or on the other hand, the interest before the yield and tax rather than operational cash flow have more information content. It is worth to remember that the results of Subramaniam, Neckatachalam (2007) and stiffen $\operatorname{rapp}(2010)$ are related. The investors are proposed that in their investments to consider the criteria for interest before the tax. Considering the role of information asymmetry in effectiveness and better performance of capital market, it is proposed that Tehran's stock exchange organization move toward development and improvement, activities for increasing information clarity and decreasing information asymmetry, better performance of available activities such as the instruction of disclosing the firm's listed information and so on. Also, it is required that reducing information asymmetry is a general satisfactory goal for planners of accounting process and applying the standards.

The enthusiasts for investigating the relationship between the interest before the yield, tax and operational cash flow with firms' stock output use other models such as "the domain of proposing sale price difference and sale stock" and nonlinear models such as fuzzy and neural network are used, too.

\section{References}

Aharony, J., Falk, H., \& Yehuda, N. (2006). Corporation Life cycle and the value relevance of cash flow versus accrual financial information. School of economics and management, Italy, working paper, 34.

Ashiq, A. (1994). The Incremental Information Content of Earning, Working capital From Operation and Cash Flow. Journal of Accounting Research, 32(1).

Bhattacharya, N., Desai, H., \& Venkataraman, K. (2010). Earnings Quality and Information Asymmetry: Evidence from Trading Costs. Under review in second round at Contemporary Accounting Review.

Dechow, P. M., Kothari, S. P., \& Watts, R. L. (1998). The Relation between Earnings and Cash Flows. Journal of Accounting and Economics, 25(1), 133-168. http://dx.doi.org/10.1016/S0165-4101(98)00020-2

Easton, P., Harris, T., \& Ohlson. J. (1992). Aggregate Accounting Earning can Explain most of Security Returns: The Case of Long Returns Intervals. Journal of Accounting and Economics. http://dx.doi.org/10.1016/0165-4101(92)90015-T

Java, H. (2009). Asymmetry in Cash Flows and Accounting Conservatism. Retrieved from http://www.ssrn.com

Rayburn, J. (1986). The Association of Operating Cash flow and accrual With Security returns. Journal of Accounting Research, 24, 112-133. http://dx.doi.org/10.2307/2490732

Steffen, R. M. (2010). Information Asymmetries and the Value Relevance of Cash Flow and Accounting Figures: Empirical Analysis and Implications for Managerial accounting. Retrieved from http://ssrn.com/abstract=1555652

Subramanyam, K. R., \& Venkatachalam, M. (2007). Earnings, Cash Flows, and Ex-Post Intrinsic Value of Equity. The Accounting Review, 457-481. http://dx.doi.org/10.2308/accr.2007.82.2.457

Wasan, S., \& Boone, P. (2010). Do Accruals Exacerbate Information Asymmetry in the Market? Advances in Accounting, 26(1), 66-78. http://dx.doi.org/10.1016/j.adiac.2009.10.002

\section{Copyrights}

Copyright for this article is retained by the author(s), with first publication rights granted to the journal.

This is an open-access article distributed under the terms and conditions of the Creative Commons Attribution license (http://creativecommons.org/licenses/by/3.0/). 